\title{
Impact of long-term glucose variability on coronary atherosclerosis progression in patients with type 2 diabetes: a 2.3 year follow-up study
}

Suhua $\mathrm{Li}^{1 \dagger}$, Xixiang Tang ${ }^{2,3 \dagger}$, Yanting Luo ${ }^{1 \dagger}$, Bingyuan $\mathrm{Wu}^{1}$, Zhuoshan Huang ${ }^{1}$, Zexiong Li', Long Peng ${ }^{1}$, Yesheng Ling ${ }^{1}$, Jieming Zhu' ${ }^{1}$ Junlin Zhong ${ }^{4^{*}}$, Jinlai Liu ${ }^{1 *}$ (C) and Yanming Chen ${ }^{2^{*}}$

\begin{abstract}
Background: Glycemic variability (GV) confers a risk of cardiovascular events. In this study, we aimed to investigate whether long-term GV has an impact on coronary atherosclerosis progression in patients with type 2 diabetes mellitus (T2DM).

Methods: A total of 396 patients with T2DM who had coronary computed tomography angiography and laboratory data available at baseline and for follow-up evaluations [median 2.3 (1.8-3.1) years] were included. Fasting plasma glucose (FPG) was measured every 1-3 months, and $\mathrm{HbA} 1 \mathrm{c}$ was measured quarterly. The coefficient of variation (CV) of HbA1c and FPG were calculated as measures of GV. Quantitative assessment of coronary plaques was performed by measuring the annual change and progression rate of total plaque volume (TPV). Significant progression was defined as annual TPV progression $\geq 15 \%$. Multivariable regression analyses were used to assess the effects of GV on atherosclerosis progression.

Results: In the 396 patients, the annual change in TPV was $12.35 \pm 14.23 \mathrm{~mm}^{3}$, and annual progression rate was $13.36 \pm 12.69 \%$. There were $143(36.11 \%)$ patients with significant progression, and they had a significantly higher CV-HbA1c $(P<0.001)$ and CV-FPG $(P<0.001)$ than those without significant progression. In multivariable regression analyses, both CV-HbA1c and CV-FPG were independent predictors of annual change in TPV [CV-HbA1c: $\beta=0.241$ $(0.019-0.462), P=0.034 ; C V-F P G . \beta=0.265(0.060-0.465), P=0.012]$, annual TPV progression [CV-HbA1c: $\beta=0.214$ $(0.023-0.405), P=0.029 ; C V-F P G . \beta=0.218(0.037-0.399), P=0.019]$, and significant atherosclerosis progression [CVHbA1c: odds ratio $[O R]=1.367(1.149-1.650), P=0.010 ; C V-F P G$ : $O R=1.321(1.127-1.634), P=0.013]$.
\end{abstract}

\footnotetext{
*Correspondence: zhongjl26@mail.sysu.edu.cn; liujinl@mail.sysu.edu.cn; chyanm@mail.sysu.edu.cn

${ }^{\dagger}$ Suhua Li, Xixiang Tang and Yanting Luo contributed equally to this work.

${ }^{1}$ Department of Cardiovascular Medicine, The Third Affiliated Hospital

of Sun Yat-Sen University, Guangzhou 510630, China

2 Department of Endocrinology \& Metabolism, Guangdong Provincial Key

Laboratory of Diabetology, The Third Affiliated Hospital of Sun Yat-Sen

University, Guangzhou 510630, China

${ }^{4}$ Department of Ultrasonography, The Third Affiliated Hospital of Sun

Yat-Sen University, Guangzhou 510630, China

Full list of author information is available at the end of the article
}

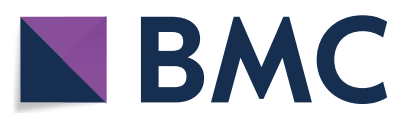

(c) The Author(s) 2020. This article is licensed under a Creative Commons Attribution 4.0 International License, which permits use, sharing, adaptation, distribution and reproduction in any medium or format, as long as you give appropriate credit to the original author(s) and the source, provide a link to the Creative Commons licence, and indicate if changes were made. The images or other third party material in this article are included in the article's Creative Commons licence, unless indicated otherwise in a credit line to the material. If material is not included in the article's Creative Commons licence and your intended use is not permitted by statutory regulation or exceeds the permitted use, you will need to obtain permission directly from the copyright holder. To view a copy of this licence, visit http://creativeco mmons.org/licenses/by/4.0/. The Creative Commons Public Domain Dedication waiver (http://creativecommons.org/publicdomain/ zero/1.0/) applies to the data made available in this article, unless otherwise stated in a credit line to the data. 
Conclusions: Long-term GV is associated with accelerated progression of coronary atherosclerosis independent of conventional risk factors in patients with T2DM.

Trial registration ClinicalTrials.gov (NCT02587741), October 27, 2015; retrospectively registered

Keywords: Type 2 diabetes, Glycemic variability, Coronary computed tomography angiography, Atherosclerosis progression

\section{Background}

Type 2 diabetes mellitus (T2DM) represents a major risk factor for the development of coronary artery disease (CAD) and cardiovascular mortality [1]. Evidence indicates that DM is associated with significantly higher coronary artery total plaque volume, independent of other CAD risk factors [2]. In addition, patients with T2DM have greater coronary plaque progression, and in particular significantly greater progression of plaques associated with adverse outcomes [3]. Risk factors related to plaque progression in patients with T2DM include hypertension [2], male sex, and mean plaque burden $>75 \%$ at baseline [3].

Intravascular ultrasound is considered as the gold standard for evaluating coronary plaques. However, it is an invasive examination and thus is limited with respect to clinical follow-up [4]. Coronary computed tomography angiography (CTA) has been extensively studied, and is considered as a non-invasive and convenient tool with acceptable accuracy to quantitatively measure coronary artery plaque volume [5-7].

In patients with $\mathrm{T} 2 \mathrm{DM}$, an abundant of evidence has indicated that glycemic variability (GV), independent of hyperglycemia, is associated with an increased risk of cardiovascular diseases [8], adverse changes of cardiac structure and function $[9,10]$, ischemic stroke [11], cardiovascular mortality [12], all-cause mortality [13-16], and coronary plaque vulnerability [17-21]. However, little is known about the impact of GV on coronary plaque progression in patients with T2DM.

Therefore, the objective of this study was to examine the association of long-term GV with coronary plaque progression among patients with T2DM, independent of conventional CAD risk factors.

\section{Methods}

\section{Study population}

This was a prospective observational cohort study conducted at the Third Affiliated Hospital of Sun Yat-sen University between January 2013 and December 2019. Consecutive patients with T2DM who underwent 320slice coronary CTA at baseline and follow-up and had laboratory data from baseline and follow-up evaluations were included. The reasons for these patients receiving coronary CTA including angina-like symptoms, an abnormal echocardiogram, positive stress ECG test, abnormal myocardial perfusion scintigraphy, and/ or elevated cardiovascular risk [22]. The period between coronary CTA scans was at least 18 months. T2DM was diagnosed according to the 1999 criteria of the World Health Organization (WHO) [23]. Patients with plaque-free coronary arteries at baseline, a history of percutaneous coronary intervention or coronary bypass surgery, $<10$ fasting plasma glucose (FPG) measurements or $<5 \mathrm{HbA} 1 \mathrm{c}$ measurements, or inadequate imaging quality for analysis were excluded. Ethical approval was obtained from the Third Affiliated Hospital of Sun Yatsen University Network Ethics Committee. Informed consent was obtained from all participants.

\section{Data collection and follow-up}

A detailed medical history was obtained from all patients using a standardized questionnaire. Data collected included age, sex, duration of diabetes, comorbidities (i.e., hypertension, hyperlipidemia, and malignancy), lifestyle habits (smoking status and alcohol consumption), the use of medications (i.e., antihypertensive agents, antiplatelet drugs, and statins), current hypoglycemic treatments (i.e., oral hypoglycemic drugs, insulin injections), and hypoglycemic events during the year prior to the collection of baseline data. Body height and weight, systolic blood pressure (SBP) and diastolic blood pressure (DBP), and laboratory studies were obtained at baseline. The laboratory tests included blood urea nitrogen (BUN), creatinine, uric acid (UA), triglycerides, total cholesterol, high-density lipoprotein cholesterol (HDL-C), and low-density lipoprotein cholesterol (LDL-C). Blood was collected after an 8-h overnight fast, and analyzed with a HITACHI 7180 automatic-analyzer. FPG and 2-h postprandial blood glucose (2h-PBG) were measured every 1-3 months, depending on the degree of glycemic control, using the glucose oxidase method. HbA1c was measured quarterly by the D-10 Hemoglobin Testing Program (Bio-Rad) with high-performance liquid chromatography (HPLC). Coronary CTA (320-slice) was performed with an Aquilion ONE CT scanner (Toshiba Medical Systems, Ottawara, Japan) to assess coronary atherosclerosis at baseline and at the final follow-up visit. Anti-hyperglycemic treatments and lifestyle interventions were 
evaluated by specialist physicians during follow-up visits, and changes were based on glucose control status.

\section{Assessment of glycemic variability}

Participants with at least 10 FPG and 5 HbA1c measurements during the study were included in the analyses of GV. For each participant, the intra-personal mean and standard deviation (SD) of all recorded FPG and HbA1c measurements were calculated. The coefficient of variation $(\mathrm{CV})$ was defined as the ratio of the SD over the mean FPG or mean HbA1c, and the CV-HbA1c and CVFPG were considered measures of GV. Considering that the frequency of follow-up visits could influence the calculation results, the CV-HbA1c and CV-FPG were further adjusted by dividing by the square root of the ratio of total visits divided by total visits minus 1 [9-11].

\section{Acquisition and analysis of coronary CTA images}

The 320-slice coronary CTA was performed according to a predefined standard operating procedure to ensure optimal image quality. An oral dose (50-100 mg) of metoprolol (Astrazeneca, Wuxi, China) was given to patients with a resting heart rate $>70 \mathrm{bpm}$. Isovue- 370 (50-100 ml, Bracco Diagnostics, Guangzhou, China) was injected intravenously at a flow rate of $6.0 \mathrm{ml} / \mathrm{s}$, followed by a $20 \mathrm{ml}$ saline flush at a flow rate of $4.0 \mathrm{ml} / \mathrm{s}$. Coronary CTA was performed with $0.5-\mathrm{mm}$ detector element, gantry rotation time of $350 \mathrm{~ms}$, and up to $16 \mathrm{~cm}$ of coverage in the $\mathrm{Z}$ direction. Tube voltage was $100-135 \mathrm{kV}$, and the maximal tube current was $400-580 \mathrm{~mA}$. The follow-up scan was performed at least 18 months after the initial CTA using the same protocol.

Datasets were transferred to a workstation for quantitative assessment of coronary plaques using semi-automated plaque analysis software. All images were analyzed by 2 experienced radiologists with more than 4 years of experience in evaluating cardiac $\mathrm{CT}$ who were blinded to patient clinical data. Coronary arteries were assessed according to the modified 17-segment American Heart Association classification [24, 25]. Baseline and followup coronary lesions were matched using branch points as landmarks [25]. The lumen and vessel borders were automatically detected by the software in the 3-dimensional reconstructed images, and then manually corrected by the radiologists. Total plaque volume (TPV) based on a per-patient analysis was calculated by a calculus sum of the cross-sectional area of the vessel border minus the cross-sectional area of the lumen. The annual change and progression rate of TPV were calculated. Clinically significant atherosclerosis progression was defined as an annual TPV progression rate $\geq 15 \%$ [26]. The percentage of patients with significant progression was calculated.

\section{Statistical analysis}

Database management and statistical analysis was performed by using SPSS version 22.0 software for Windows (SPPS Inc., Chicago, IL, USA). Descriptive statistics were presented as mean \pm standard deviation for continuous variables, or as number and percentage for categorical variables. Pearson chi-square tests for trend, and Spearman rank correlation tests were used to examine relations between coronary artery plaque parameters and GV. Univariate linear regression analysis was performed to assess the non-adjusted relations between GV and the annual change and progression rate of TPV, and to evaluated the association between GV and clinically significant atherosclerosis progression. Multivariate regression models were performed to adjust for confounding factors, including age, sex, body mass index (BMI), diabetes duration, smoking status, alcohol consumption, hypertension, hypoglycemia rate, triglycerides, LDL-C, HDL-C, FPG, 2h-FBG, HbA1c, estimated glomerular filtration rate (eGFR), UA, Homeostatic Model Assessment of Insulin Resistance (HOMA-IR), urine albumin-to-creatinine ratio (UACR), and medications. A 2-tailed $P$ value $<0.05$ was considered to indicate statistical significance.

\section{Results}

\section{Patient selection}

In this cohort study, a total of 791 consecutive patients who had paired coronary CTA and laboratory data at both baseline and follow-up evaluations were enrolled. Participants with plaque-free coronary arteries $(\mathrm{n}=45),<10$ FPG measurements or $<5$ HbA1c measurements $(n=213)$, a history of percutaneous coronary intervention $(n=93)$ or coronary bypass surgery $(n=13)$, and inadequate imaging quality for analysis $(\mathrm{n}=31)$ were excluded. Finally, a total of 396 patients (200 males, 196 females; mean age $46.30 \pm 10.9$ years) with 1577 coronary segments with visible plaques were included in the analysis (Fig. 1). The median diabetes duration was 4.0 (interquartile range [IQR]: 2.0-8.0) years at baseline, and the median follow-up duration was 2.3 (IQR: $1.8-3.1$ ) years. The mean baseline HbA1c was $6.7 \pm 1.4 \%$, and FPG was $6.9 \pm 2.3 \mathrm{mmol} / \mathrm{L}$.

\section{Total plaque volume at baseline and follow-up}

The initial TPV of all participants was $108.60 \pm 42.61$ $\mathrm{mm}^{3}$ based on a per-patients analysis. The absolute change in TPV was $28.34 \pm 33.72 \mathrm{~mm}^{3}$ after a median follow-up of 2.3 (IQR: 1.8-3.1) years. Thus, the mean annual change in TPV was $12.35 \pm 14.23 \mathrm{~mm}^{3}$, and the mean annual TPV progression rate was $13.36 \pm 12.69 \%$ (Fig. 2). There were 143 (36.11\%) patients with clinically significant atherosclerosis progression (annual TPV 
A total of 791 participants enrolled in the stduy

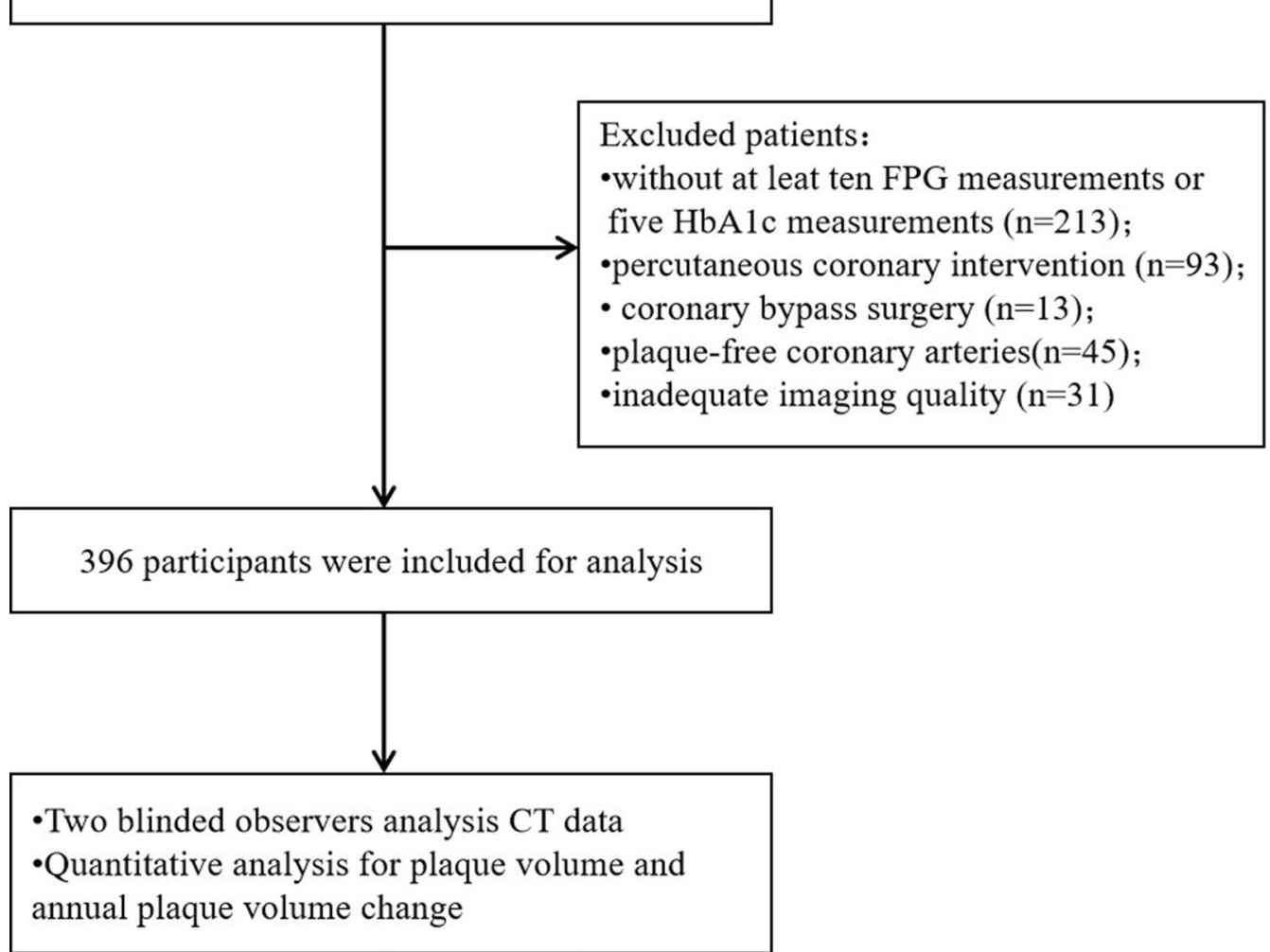

Fig. 1 Flowchat of the present study

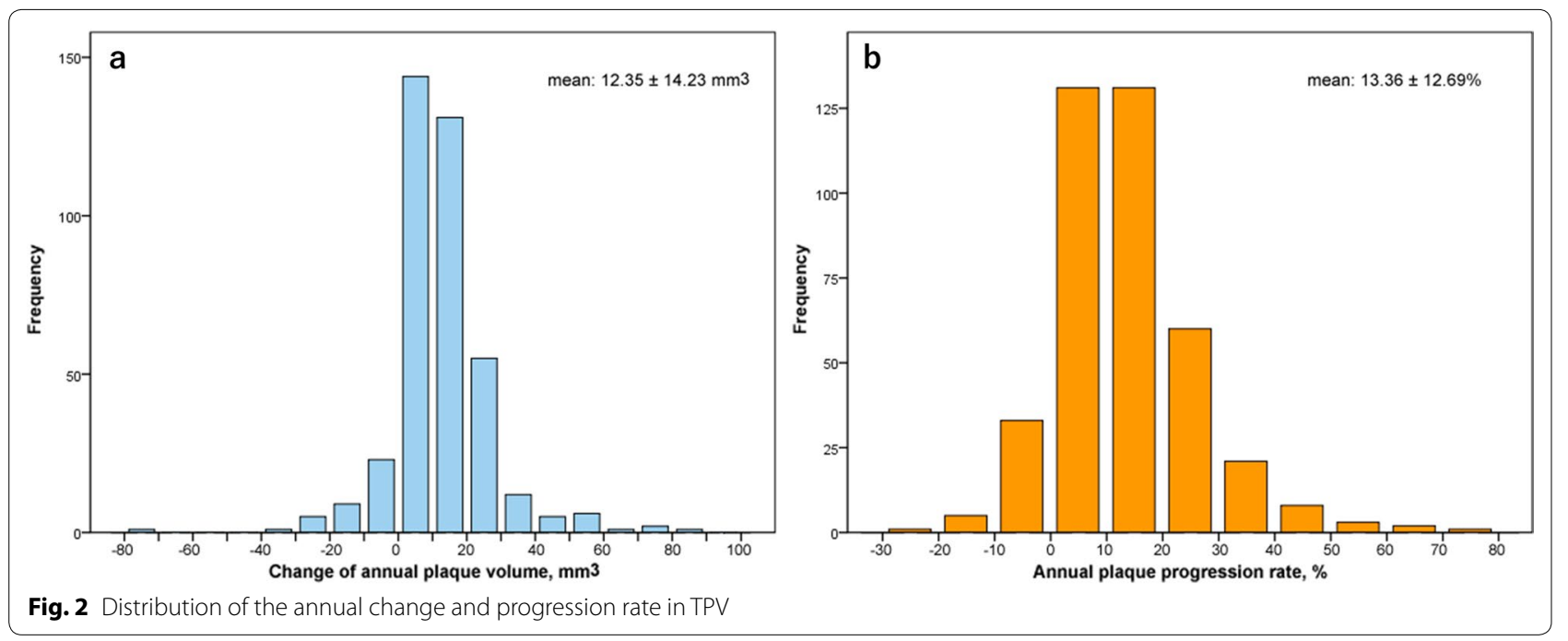

progression rate $\geq 15 \%)$, while the other 253 (63.9\%) patients did not have significant progression. Representative imaging studies showing progression in total plaque volume were shown in Fig. 3.
Patient baseline sociodemographic and clinical data were summarized in Table 1. Compared to patients without atherosclerosis progression, HbA1c, FPG, 2h-PBG, HOMA-IR, total cholesterol, and LDL-C were higher in 

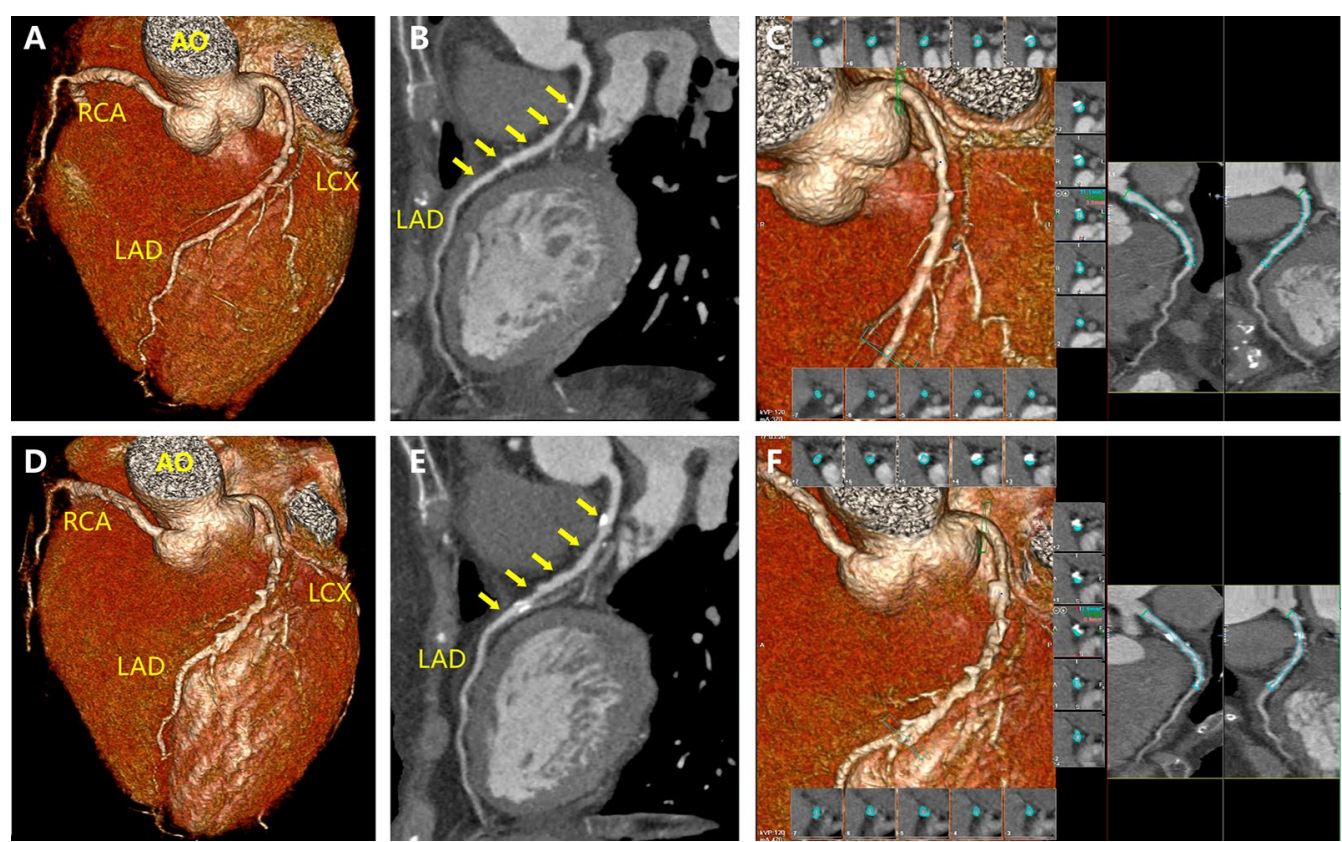

Fig. 3 Representative imaging for the change of the total plaque volume at the beginning and the follow-up. The 3-dimensional reconstruction and analysis of coronary CTA images of a 60-year-old female patient with type 2 diabetes were performed. The baseline CTA showed a moderate stenosis in the proximal segment of the left anterior descending coronary artery $(\mathbf{a}, \mathbf{b})$, with a total plaque volume of $119 \mathrm{~mm}^{3}(\mathbf{c})$. After a 2.8 -year follow up, clinically significant progression $\left(\mathbf{d}-\mathbf{f}\right.$ ) was observed, with the total plaque volume progressed to $194 \mathrm{~mm}^{3}$. The annual progression rate in total plaque volume was $22.51 \%$

patients with progression (all, $P<0.05$ ), while the percentages of patients who consumed alcohol, used antiplatelet medications, and took statins were lower (all, $P<0.05)$. Although the initial TPV was lower in patients with progression, after follow-up the absolute change in TPV $(P<0.001)$, annual change in TPV $(P<0.001)$, and annual TPV progression rate $(P<0.001)$ were significantly higher than in patients without progression (Fig. 4).

\section{Glycemic variability}

The mean CV-HbA1c was $16.73 \pm 7.87 \%$ in all patients, and the mean CV-FPG was $13.80 \pm 10.20 \%$. When compared to patients without atherosclerosis progression, patients with progression have markedly higher $\mathrm{GV}$, as indicated by CV-HbA1c $(18.96 \pm 9.83 \%$ vs. $15.48 \pm 6.17$, $P<0.001)$ and CV-FPG $(16.84 \pm 12.14$ vs. $12.08 \pm 8.47$, $P<0.001)$. As shown in Fig. 5, both CV-HbA1c and CVFPG were positively correlated with TPV annual change and progression rate (all, $P<0.001$ ).

\section{Linear regression analysis assessing the effect of glycemic variability on atherosclerosis progression}

In the univariate analysis, potential factors associated with TPV annual change and progression rate were HbA1C, CV-HbA1C, FPG, CV-FPG, 2h-FBG, LDLC, HOMA-IR, use of anti-platelet drugs, use of statins, and alcohol consumption (Table 2). In the multivariate regression analysis adjusted for age, sex, BMI, diabetes duration, smoking, alcohol consumption, hypertension, hypoglycemia rate, triglycerides, LDL-C, HDL-C, FPG, 2h-FBG, HbA1c, eGFR, UA, HOMA-IR, UACR, and medications, elevated indices of $\mathrm{GV}$, both $\mathrm{CV}-\mathrm{HbA1C}$ and CV-FPG, remained strong determinants of annual change in TPV [CV-HbA1C: $\beta(95 \% \mathrm{CI})=0.241(0.019-$ 0.462), $P=0.034$, and CV-FPG: $\beta(95 \% \mathrm{CI})=0.265$ (0.060-0.465), $P=0.012]$ and annual TPV progression rate $[\mathrm{CV}$-HbA1C: $\beta(95 \% \mathrm{CI})=0.214(0.023-0.405)$, $P=0.029$, and CV-FPG: $\beta(95 \% \mathrm{CI})=0.218(0.037-$ 0.399 ), $P=0.019$ ] (Table 2).

\section{Logistic regression analysis assessing the value of GV for predicting clinically significant atherosclerosis progression}

In the univariate analysis, potential factors associated with clinically significant atherosclerosis progression included HbA1C, CV-HbA1C, FPG, CV-FPG, 2h-FBG, LDL-C, HOMA-IR, use of anti-platelet drugs, use of statins, use of glucosidase inhibitors, and alcohol consumption (Table 3). In the multivariate analysis adjusting for age, sex, BMI, diabetes duration, smoking, alcohol consumption, hypertension, hypoglycemia rate, triglycerides, LDL-C, HDL-C, FPG, 2h-FBG, HbA1c, eGFR, 
Table 1 Baseline characteristics of patients with or without clinically significant atherosclerosis progression

\begin{tabular}{|c|c|c|c|c|}
\hline Variables & Total & $\begin{array}{l}\text { Non-progression } \\
(n=253)\end{array}$ & $\begin{array}{l}\text { Progression } \\
(n=143)\end{array}$ & $P$-value \\
\hline Age, years & $63.0 \pm 10.9$ & $63.5 \pm 10.3$ & $62.1 \pm 11.9$ & 0.222 \\
\hline Male, n (\%) & $200(50.5)$ & $126(49.8)$ & $74(51.7)$ & 0.659 \\
\hline $\mathrm{BMI}, \mathrm{kg} / \mathrm{m}^{2}$ & $26.4 \pm 5.5$ & $26.4 \pm 5.4$ & $26.5 \pm 5.6$ & 0.798 \\
\hline Smoking, $n(\%)$ & $107(27.0)$ & $65(25.7)$ & $42(29.4)$ & 0.328 \\
\hline Alcohol, n (\%) & $51(12.9)$ & $40(15.8)$ & $11(7.7)$ & 0.021 \\
\hline Hyperlipidemia, n (\%) & $121(30.6)$ & $73(28.9)$ & 48 (33.6) & 0.328 \\
\hline Hypertension, n (\%) & $266(67.2)$ & $177(70.0)$ & $89(62.2)$ & 0.116 \\
\hline $\mathrm{SBP}, \mathrm{mmHg}$ & $140.0 \pm 18.8$ & $140.5 \pm 19.6$ & $138.9 \pm 16.9$ & 0.380 \\
\hline $\mathrm{DBP}, \mathrm{mmHg}$ & $79.3 \pm 11.6$ & $79.7 \pm 11.7$ & $78.6 \pm 11.5$ & 0.394 \\
\hline $\mathrm{HR}, \mathrm{bpm}$ & $76.9 \pm 12.2$ & $77.0 \pm 12.7$ & $76.5 \pm 11.4$ & 0.694 \\
\hline \multicolumn{5}{|l|}{ Diabetes-related variables } \\
\hline Diabetes duration, years & $4.0(2.0-8.0)$ & $4.3(2.0-9.0)$ & $3.5(2.0-6.0)$ & 0.125 \\
\hline $\mathrm{HbA1c}, \%$ & $6.7 \pm 1.4$ & $6.5 \pm 1.1$ & $7.1 \pm 1.7$ & $<0.001$ \\
\hline Number of $\mathrm{HbA} 1 \mathrm{c}$ measurements, $\mathrm{n}$ & $7.5 \pm 1.8$ & $7.4 \pm 1.8$ & $7.7 \pm 1.9$ & 0.436 \\
\hline Time interval between $\mathrm{HbA} 1 \mathrm{c}(\mathrm{s})$, months & $4.0(3.5-4.6)$ & $4.0(3.8-4.5)$ & $3.9(3.4-4.7)$ & 0.384 \\
\hline $\mathrm{CV}-\mathrm{HbA} 1 \mathrm{c}, \%$ & $16.73 \pm 7.87$ & $15.48 \pm 6.17$ & $18.96 \pm 9.83$ & $<0.001$ \\
\hline $\mathrm{FPG}, \mathrm{mmol} / \mathrm{L}$ & $6.9 \pm 2.3$ & $6.57 \pm 1.72$ & $7.49 \pm 3.06$ & 0.001 \\
\hline Number of FPG measurements, $n$ & $9.9 \pm 2.0$ & $9.8 \pm 1.9$ & $10.1 \pm 2.3$ & 0.226 \\
\hline Time interval between FPGs, months & $3.0(2.6-3.5)$ & $3.1(2.7-3.6)$ & $2.9(2.4-3.3)$ & 0.363 \\
\hline CV-FPG, \% & $13.80 \pm 10.20$ & $12.08 \pm 8.47$ & $16.84 \pm 12.14$ & $<0.001$ \\
\hline $2 \mathrm{~h}-\mathrm{PBG}, \mathrm{mmol} / \mathrm{L}$ & $9.65 \pm 2.40$ & $9.20 \pm 1.74$ & $10.44 \pm 3.10$ & $<0.001$ \\
\hline $\mathrm{FCP}, \mathrm{nmol} / \mathrm{L}$ & $1.83 \pm 1.26$ & $1.83 \pm 1.24$ & $1.82 \pm 1.30$ & 0.933 \\
\hline $2 \mathrm{~h}-\mathrm{PCP}, \mathrm{nmol} / \mathrm{L}$ & $4.63 \pm 2.48$ & $4.69 \pm 2.54$ & $4.53 \pm 2.36$ & 0.536 \\
\hline Fasting insulin, mU/L & $79.21 \pm 50.43$ & $77.35 \pm 50.01$ & $82.51 \pm 51.16$ & 0.328 \\
\hline 2h-insulin, mU/L & $220.99 \pm 141.71$ & $226.71 \pm 139.48$ & $210.86 \pm 145.52$ & 0.285 \\
\hline HOMA-IR & $24.21 \pm 19.12$ & $22.27 \pm 15.59$ & $27.65 \pm 23.81$ & 0.016 \\
\hline UACR, mg/g & $1.65(0.85-3.72)$ & $1.46(0.79-4.18)$ & $1.76(0.85-3.02)$ & 0.921 \\
\hline Hypoglycemia rates, $\%$ & $26(6.6)$ & $17(6.7)$ & $9(6.3)$ & 0.870 \\
\hline \multicolumn{5}{|l|}{ Other laboratory tests } \\
\hline $\mathrm{TC}, \mathrm{mmol} / \mathrm{L}$ & $4.74 \pm 1.13$ & $4.60 \pm 1.18$ & $5.00 \pm 0.99$ & 0.001 \\
\hline $\mathrm{TG}, \mathrm{mmol} / \mathrm{L}$ & $1.49(1.00-2.15)$ & $1.49(1.02-2.20)$ & $1.50(0.94-2.11)$ & 0.637 \\
\hline $\mathrm{HDL}-\mathrm{C}, \mathrm{mmol} / \mathrm{L}$ & $1.11 \pm 0.28$ & $1.10 \pm 0.26$ & $1.12 \pm 0.31$ & 0.162 \\
\hline $\mathrm{LDL}-\mathrm{C}, \mathrm{mmol} / \mathrm{L}$ & $2.95 \pm 0.93$ & $2.83 \pm 0.94$ & $3.15 \pm 0.86$ & 0.001 \\
\hline apoA1, g/L & $1.35 \pm 0.29$ & $1.34 \pm 0.32$ & $1.38 \pm 0.22$ & 0.084 \\
\hline apoB100, g/L & $1.12 \pm 0.42$ & $1.09 \pm 0.42$ & $1.16 \pm 0.41$ & 0.088 \\
\hline LP_a, mg/L & $193.3 \pm 246.0$ & $194.2 \pm 254.0$ & $191.52 \pm 232.0$ & 0.916 \\
\hline $\mathrm{Cr}, \mu \mathrm{mol} / \mathrm{L}$ & $76.7 \pm 20.7$ & $77.0 \pm 21.6$ & $76.2 \pm 19.0$ & 0.701 \\
\hline $\mathrm{eGFR}, \mathrm{mL} / \mathrm{min} / 1.73 \mathrm{~m}^{2}$ & $83.1 \pm 19.0$ & $82.2 \pm 19.7$ & $84.8 \pm 17.8$ & 0.205 \\
\hline $\mathrm{BUN}, \mu \mathrm{mol} / \mathrm{L}$ & $5.64 \pm 1.71$ & $5.64 \pm 1.69$ & $5.64 \pm 1.74$ & 0.972 \\
\hline $\mathrm{UA}, \mu \mathrm{mol} / \mathrm{L}$ & $379.0 \pm 108.0$ & $380.0 \pm 102.3$ & $377.2 \pm 117.8$ & 0.808 \\
\hline \multicolumn{5}{|l|}{ Medications } \\
\hline Insulin, n (\%) & $83(21.0)$ & $52(20.6)$ & $31(21.7)$ & 0.807 \\
\hline Metformin, n (\%) & $234(59.0)$ & $146(57.8)$ & 88 (62.6) & 0.706 \\
\hline Glucosidase inhibitor, n (\%) & $84(21.2)$ & 45 (17.8) & $39(27.3)$ & 0.028 \\
\hline Sulfonylureas, n (\%) & $44(11.1)$ & $29(11.5)$ & $15(10.5)$ & 0.757 \\
\hline DPP-4 inhibitors/GLP-1R, n (\%) & $34(8.6)$ & $27(10.7)$ & $7(4.9)$ & 0.048 \\
\hline Glinides, n (\%) & $7(1.8)$ & $6(2.4)$ & $1(0.7)$ & 0.223 \\
\hline Anti-platelet, n (\%) & $285(72.0)$ & $196(77.5)$ & $89(62.2)$ & 0.001 \\
\hline Statin, n (\%) & $295(74.5)$ & $197(77.9)$ & $98(68.5)$ & 0.041 \\
\hline
\end{tabular}


Table 1 (continued)

\begin{tabular}{|c|c|c|c|c|}
\hline Variables & Total & $\begin{array}{l}\text { Non-progression } \\
(n=253)\end{array}$ & $\begin{array}{l}\text { Progression } \\
(n=143)\end{array}$ & $P$-value \\
\hline ACEI/ARB, n (\%) & $179(45.2)$ & $121(47.8)$ & $58(40.6)$ & 0.163 \\
\hline$\beta$-blocker, n (\%) & $122(30.8)$ & 85 (33.6) & $37(25.9)$ & 0.110 \\
\hline CCB, n (\%) & $130(32.8)$ & $90(35.6)$ & $40(28.0)$ & 0.122 \\
\hline Diuretic, n (\%) & $58(14.6)$ & $42(16.6)$ & $16(11.2)$ & 0.143 \\
\hline
\end{tabular}

Data are mean (SD), median (25th to 75th percentile) or $\mathrm{n}(\%)$

BMI, body mass index; SBP, systolic blood pressure; DBP, diastolic blood pressure; HR, heart rate; CV, coefficient of variation; FPG, fasting plasma glucose; PBG, postprandial blood glucose; FCP, Fasting C-peptide; $2 \mathrm{~h}-\mathrm{PCP}$, 2hour-postprandial C-peptide; HOMA-IR, homeostatic model assessment of insulin resistance; UACR, urine albumin-to-creatinine ratio; $\mathrm{Cr}$, plasma creatinine; $\mathrm{BUN}$, blood urea nitrogen; $\mathrm{UA}$, uric acid; TC, total cholesterol; TG, triglycerides; $\mathrm{HDL}-\mathrm{C}$, high density lipoprotein cholesterol; LDL-C, low density lipoprotein cholesterol; ACEI/ARB, angiotensin converting enzyme inhibitor/angiotensin receptor blocker; CCB, calcium channel blockers
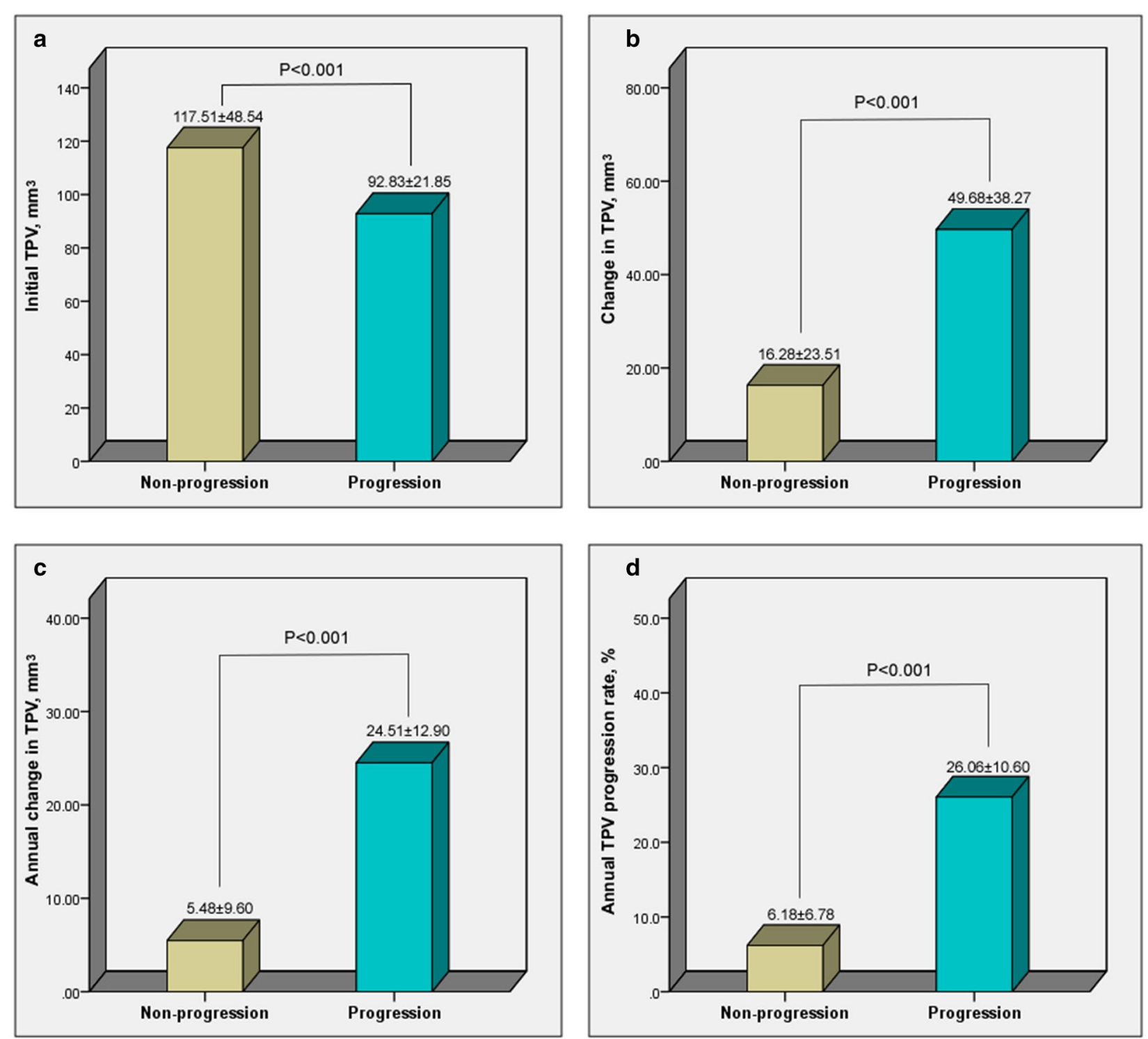

Fig. 4 Comparison between patients with non-progression and progression in coronary atherosclerosis 

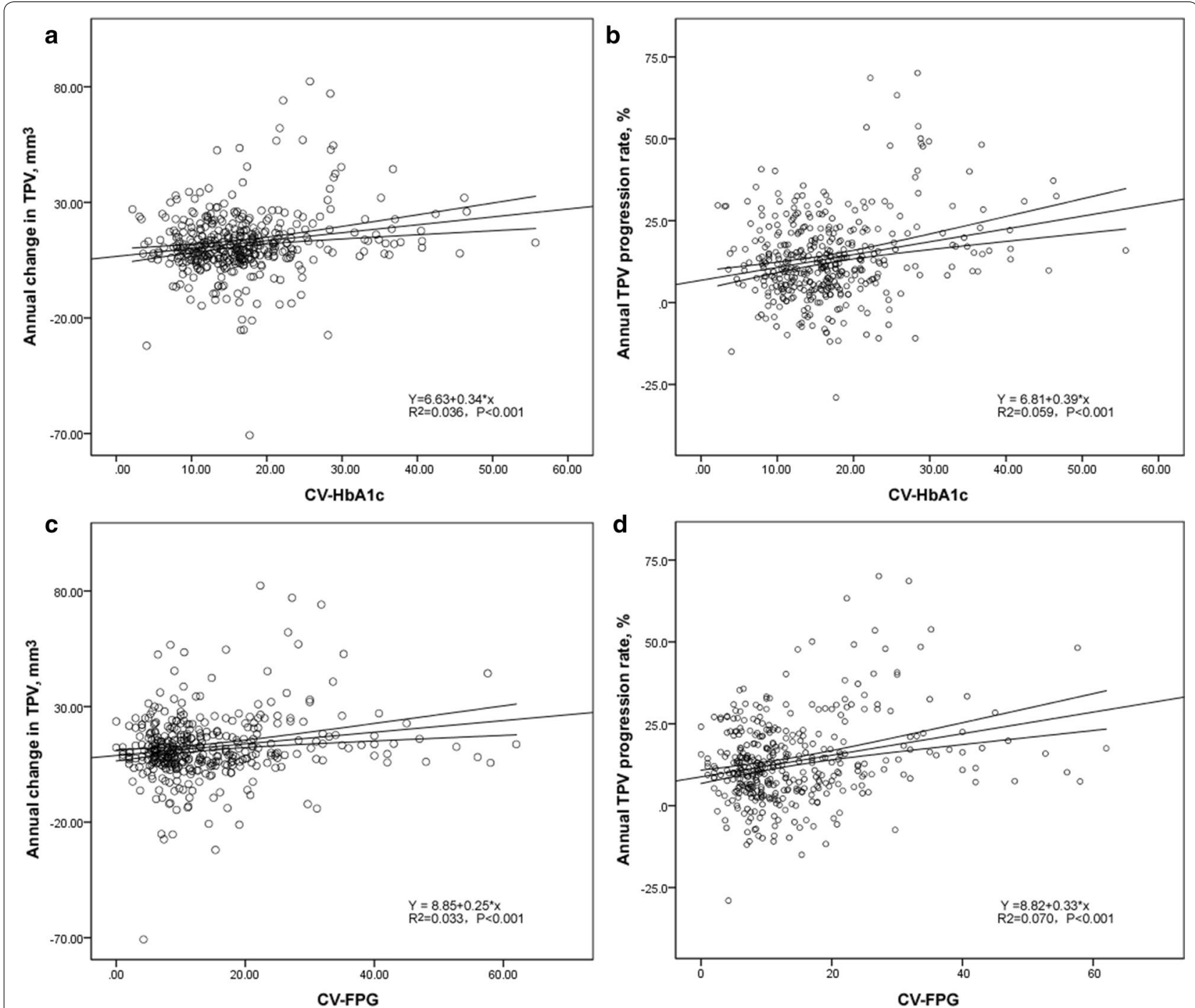

Fig. 5 Correlation between glucose variability and atherosclerosis progression. $\mathbf{a} Y=6.63+0.34 * x, R^{2}=0.036, P<0.001 . \mathbf{b} Y=6.81+0.39 * x$, $R^{2}=0.059, P<0.001 . \mathbf{c} Y=8.85+0.25 * x, R^{2}=0.033, P<0.001 . \mathbf{d} Y=8.82+0.33 * x, R^{2}=0.070, P<0.001$

UA, HOMA-IR, UACR, and medications, for each 1 unit increase in CV-HbA1c, the risk of clinically significant atherosclerosis progression increased by $36.7 \%$ [OR $(95 \%$ $\mathrm{CI})=1.367(1.149-1.650), P=0.010]$, and for each 1 unit increase in CV-FPG, the risk increased by $32.1 \%$ [OR $(95 \% \mathrm{CI})=1.321(1.127-1.634), P=0.013]$.

\section{Discussion}

The present study revealed that increased long-term GV was significantly associated with coronary artery plaque progression, independent of $\mathrm{HbA1C}, \mathrm{FPG}$, and the other conventional CAD risk factors.

It has been shown that the overall coronary plaque burden is a good predictor of future cardiovascular events
[27]. In this study, we use coronary CTA to quantitatively assess the progression of coronary atherosclerosis [28-30]. The method has been validated with respect to plaque volume in relation to histological examination and intravascular ultrasound $[4,31]$.

\section{Coronary atherosclerosis progression in T2DM}

Abundant studies have shown that T2DM influences the development and progression of $\mathrm{CAD}$, and is related to the elevated risk of cardiovascular events and mortality. $\mathrm{DM}$ is independently related to higher TPV, leading to subsequent adverse cardiac events [2]. Moreover, previous studies have indicated that DM has an incremental impact on coronary plaque progression, and associated 
Table 2 Linear regression analysis assessing the effects of potential risk factors on plaque volume progression

\begin{tabular}{|c|c|c|c|c|c|c|}
\hline \multirow[t]{2}{*}{ Variables $^{\mathrm{a}}$} & \multicolumn{3}{|c|}{ Univariate } & \multicolumn{3}{|c|}{ Multivariate $^{\mathbf{b}}$} \\
\hline & $S \beta$ & $95 \% \mathrm{Cl}$ & P-value & $S \beta$ & $95 \% \mathrm{Cl}$ & $P$-value \\
\hline \multicolumn{7}{|c|}{ Annual change in TPV } \\
\hline $\mathrm{CV}-\mathrm{HbA} 1 \mathrm{C}$ & 0.242 & $0.062,0.438$ & 0.004 & 0.241 & $0.019,0.462$ & 0.034 \\
\hline $\mathrm{HbA1C}$ & 0.250 & $0.154,0.346$ & $<0.001$ & 0.275 & $0.073,0.477$ & 0.009 \\
\hline CV-FPG & 0.233 & $0.076,0.420$ & 0.003 & 0.265 & $0.060,0.465$ & 0.012 \\
\hline FPG & 0.245 & $0.149,0.341$ & $<0.001$ & 0.270 & $0.041,0.499$ & 0.022 \\
\hline $2 h-P B G$ & 0.299 & $0.204,0.394$ & $<0.001$ & 0.251 & $0.022,0.760$ & 0.051 \\
\hline LDL-C & 0.236 & $0.140,0.332$ & $<0.001$ & 0.243 & $0.089,0.562$ & 0.023 \\
\hline HOMA-IR & 0.194 & $0.036,0.292$ & $<0.001$ & -0.046 & $-0.264,0.172$ & 0.671 \\
\hline Anti-platelet & -0.156 & $-0.254,-0.058$ & 0.002 & -0.281 & $-0.525,-0.037$ & 0.025 \\
\hline Statin & -0.130 & $-0.228,-0.032$ & 0.010 & -0.278 & $-0.508,-0.049$ & 0.019 \\
\hline Alcohol & -0.116 & $-0.214,-0.012$ & 0.021 & -0.193 & $-0.386,0.001$ & 0.052 \\
\hline \multicolumn{7}{|c|}{ Annual TPV progression rate } \\
\hline $\mathrm{CV}-\mathrm{HbA} 1 \mathrm{C}$ & 0.243 & $0.078,0.439$ & 0.006 & 0.214 & $0.023,0.405$ & 0.029 \\
\hline $\mathrm{HbA1C}$ & 0.282 & $0.187,0.377$ & $<0.001$ & 0.362 & $0.132,0.591$ & 0.003 \\
\hline CV-FPG & 0.265 & $0.069,0.460$ & 0.004 & 0.218 & $0.037,0.399$ & 0.019 \\
\hline FPG & 0.257 & $0.161,0.352$ & $<0.001$ & 0.253 & $0.039,0.467$ & 0.022 \\
\hline $2 \mathrm{~h}-\mathrm{FBG}$ & 0.316 & $0.221,0.410$ & $<0.001$ & 0.215 & $0.024,0.665$ & 0.055 \\
\hline LDL-C & 0.230 & $0.133,0.326$ & $<0.001$ & 0.295 & $0.106,0.484$ & 0.003 \\
\hline HOMA-IR & 0.205 & $0.108,0.303$ & $<0.001$ & -0.122 & $-0.324,0.080$ & 0.231 \\
\hline Anti-platelet & -0.170 & $-0.267,-0.073$ & 0.001 & -0.311 & $-0.540,-0.082$ & 0.009 \\
\hline Statin & -0.148 & $-0.246,-0.050$ & 0.003 & -0.383 & $-0.614,-0.152$ & 0.002 \\
\hline Alcohol & -0.116 & $-0.215,-0.017$ & 0.021 & -0.201 & $-0.407,-0.041$ & 0.058 \\
\hline
\end{tabular}

CV, coefficient of variation; FPG, fasting plasma glucose; PBG, postprandial blood glucose; HOMA-IR, homeostatic model assessment of insulin resistance; LDL-C, low density lipoprotein cholesterol

a The variables which got a level of $P<0.05$ in the univariate analysis was presented in this table

b Multivariate regression analysis was adjusted for age, sex, BMI, diabetes duration, smoking, alcohol consumption, hypertension, hypoglycemia rate, triglyceride, LDL-C, HDL-C, FPG, 2h-FBG, HbA1c, eGFR, UA, HOMA-IR, UACR, and medications

Table 3 Logistic regression analysis assessing the value of potential risk factors for predicting clinically significant atherosclerosis progression

\begin{tabular}{|c|c|c|c|c|c|c|}
\hline \multirow[t]{2}{*}{ Variables $^{\mathrm{a}}$} & \multicolumn{3}{|c|}{ Univariate } & \multicolumn{3}{|c|}{ Multivariate $^{\mathbf{b}}$} \\
\hline & OR & $95 \% \mathrm{Cl}$ & P-value & OR & $95 \% \mathrm{Cl}$ & $P$-value \\
\hline $\mathrm{CV}-\mathrm{HbA} 1 \mathrm{C}$ & 1.458 & $1.230,1.688$ & $<0.001$ & 1.367 & $1.149,1.650$ & 0.010 \\
\hline $\mathrm{HbA1C}$ & 1.675 & $1.483,1.897$ & $<0.001$ & 1.499 & $1.208,1.725$ & $<0.001$ \\
\hline CV-FPG & 1.445 & $1.123,1.767$ & 0.002 & 1.321 & $1.127,1.634$ & 0.013 \\
\hline FPG & 1.398 & $1.284,1.525$ & $<0.001$ & 1.301 & $1.184,1.532$ & 0.018 \\
\hline $2 h-P B G$ & 1.281 & $1.152,1.424$ & $<0.001$ & 1.465 & $0.889,3.133$ & 0.060 \\
\hline LDL-C & 1.461 & $1.164,1.835$ & 0.001 & 1.378 & $1.078,1.763$ & 0.011 \\
\hline HOMA-IR & 1.015 & $1.004,1.026$ & 0.010 & 1.010 & $0.996,1.023$ & 0.171 \\
\hline Anti-platelet & 0.479 & $0.306,0.751$ & 0.001 & 0.426 & $0.246,0.737$ & 0.002 \\
\hline Statin & 0.619 & $0.390,0.982$ & 0.042 & 0.608 & $0.412,0.807$ & 0.036 \\
\hline Glucosidase inhibitor & 1.725 & $1.058,2.814$ & 0.029 & 1.601 & $0.140,6.221$ & 0.348 \\
\hline Alcohol & 0.444 & $0.220,0.895$ & 0.023 & 0.476 & $0.223,1.014$ & 0.054 \\
\hline
\end{tabular}

CV, coefficient of variation; FPG, fasting plasma glucose; PBG, postprandial blood glucose; HOMA-IR, homeostatic model assessment of insulin resistance; LDL-C, low density lipoprotein cholesterol

a The variables which got a level of $P<0.05$ in the univariate analysis was presented in this table

b Multivariate regression analysis was adjusted for age, sex, BMI, diabetes duration, smoking, alcohol consumption, hypertension, hypoglycemia rate, triglyceride, LDL-C, HDL-C, FPG, 2h-FBG, HbA1c, eGFR, UA, HOMA-IR, UACR, and medications 
subsequent cardiac events [32-35]. There is a twofold greater progression in TPV in diabetic patients than nondiabetic patients [32]. In this study, we found that the annual TPV progression rate in patients with T2DM was approximately $13 \%$, and more than one-third of patients demonstrated clinically significant coronary atherosclerosis progression. In addition, our results showed that poor blood glucose control (elevated HbA1c and FPG) were independent risk factors for atherosclerosis progression; a finding consistent with results reported by Berry et al. [36]. In addition, previous studies showed that male sex, mean plaque burden $>75 \%$ at baseline [3], statin use and hypertension [2] were also associated with plaque progression in patients with T2DM. Similarly, our results showed that several conventional risk factors, such as LDL-C level, anti-platelet drug use, and statin use, were independently associated with the annual TPV progression rate and clinically significant atherosclerosis progression. Different from previous studies, we showed that increased $\mathrm{CV}-\mathrm{HbA} 1 \mathrm{C}$ and $\mathrm{CV}$-FPG were indicators of coronary plaque progression, independent of $\mathrm{HbA} 1 \mathrm{c}$, FPG, and the other conventional risk factors.

\section{$\mathrm{GV}$ and the risk of coronary atherosclerosis progression}

It has been shown that a higher GV is accompanied by an unfavorable metabolic profile and is associated with an increased risk of developing complications and mortality in patients with DM [37-39]. Abundant evidence has indicated that increased long-term GV, assessed by longterm fluctuations of $\mathrm{HbA1c}$ or FPG, can predict the risk of CVD [14, 40-44] in patients with T2DM, the prognosis of acute lung diseases in patients with DM [45], and malignancies in the general population [46]. Increased GV after transcatheter aortic valve implantation is associated with an increased risk of major complications within 30 days [47], and reducing GV may represent a new therapeutic strategy for preventing the development of heart failure with preserved ejection fraction in patients with T2DM [48]. In addition, combining GV and HbA1c may achieve the highest accuracy for determining thrombotic risk [49]. Furthermore, studies have shown that glucose fluctuations strongly contribute to increased coronary plaque vulnerability at the culprit [17, $18]$ and non-culprit lesions of acute coronary syndrome [19-21]. Therefore, elevated GV may promote coronary atherosclerosis progression, which is the primary contributor of cardiovascular events. However, there is little data regarding the role of long-term GV in coronary atherosclerosis progression in patients with T2DM and stable CAD. The present study fills the gap in knowledge of the relation between long-term GV and the risk of CVD, which is one of strengths of the present study. The present study provides further evidence that long-term GV is independently associated with coronary plaque progression before the occurrence of clinical cardiovascular events. This may partly explain the finding of our previous studies, which demonstrated that GV was a novel risk factor for both the long-term adverse changes in cardiac function $[9,10]$ and 10-year risk of CVD in patients with T2DM [8]. Our findings suggest that maintaining longterm glycemic stability for patients with T2DM may delay the progression of CAD and improve clinical outcomes.

The present study explored the role of GV on coronary atherosclerosis progression, and the results may partly explain why GV contributes to adverse cardiovascular events and CVD-related mortality. Of note, it is very important to evaluate the effects of anti-diabetic agents on $\mathrm{GV}$, and their potential to attenuate the progression of coronary atherosclerosis [50, 51]. Recent evidence has indicated that DPP-4 inhibitors can improve GV and stabilize coronary artery plaques to a degree greater than that of usual medical care $[52,53]$. Other emerging therapeutic agents, such as SGLT2 inhibitors, have also been shown to effectively reduce glucose fluctuations [54]. However, whether they can delay, or even reverse the progression of atherosclerosis, remains unclear. More studies should be designed to explore the best hypoglycemic therapies for improving GV and decreasing atherosclerosis progression.

\section{Potential mechanisms by which GV affects coronary atherosclerosis progression}

The mechanisms by which increased GV contribute to coronary artery plaque progression in T2DM patients are yet to be elucidated. There are several potential explanations. Important drivers of DM associated with atherosclerosis progression and plaque instability include oxidative stress, inflammation, endothelial dysfunction, and alterations in mineral metabolism [55-58]. Positive correlations among long-term GV (HbA1c-SD) and short-term GV (the mean amplitude of glycemic excursions) with markers of oxidative stress and inflammation in T2DM patients have been reported [59], which suggests that both acute and chronic glucose fluctuations can induce oxidative stress and chronic inflammation. Thus, glucose fluctuations can enhance inflammation and oxidative stress $[60,61]$, elevate the adhesion of monocytes to endothelial cells, cause cell apoptosis [62], and promote endothelial senescence [63], subsequently leading to cardiovascular injury and dysfunction. In addition, glucose instability strongly predicts an increased incidence of hypoglycemia in patients with DM [64]. The underlying mechanism by which hypoglycemia increases CVD risk may be the release of inflammatory cytokines, increased platelet activation, endothelial dysfunction, 
and a sympatho-adrenal response that might induce arrhythmias and increase cardiac workload [65-67].

\section{Limitations}

The present study has several limitations. First, it was an observational cohort study performed at a single center, so residual confounders are hard to avoid and the results should be interpreted with some caution. Second, the values and intervals in FPG and HbA1c measurements varied for each subject during the follow-up period, although the effect of the frequency of FPG and HbA1c measurements on variability was adjusted. Third, coronary CTA was performed due to suspicion of CAD according to the clinical judgment of the referring physician. This study enrolled patients that underwent coronary CTA for suspected CVD; it did not include asymptomatic patients with normal electrocardiograms, which may cause a selection bias. Fourth, only quantitative CTA analysis was performed for visually determined plaques at the baseline and follow-up coronary CTA; qualitative analysis of coronary plaques was unavailable. In addition, measurement of plaque volume may be affected by technical factors such as tube voltage and contrast material injection rate.

\section{Conclusions}

The current study demonstrated that long-term GV was associated with accelerated progression of coronary plaques, independent of conventional risk factors. Further studies are warranted to assess the effect of maintaining long-term glucose stability on coronary plaque progression and its relations to clinical outcomes.

\begin{abstract}
Abbreviations
CAD: Coronary artery diseases; DM: Diabetes mellitus; T2DM: Type 2 diabetes mellitus; GV: Glycemic variability; CV: Coefficient of variation; FPG: Fasting plasma glucose; WHO: World Health Organization; SBP: Systolic blood pressure; DBP: Diastolic blood pressure; BUN: Blood urea nitrogen; UA: Uric acid; HDL-C: High-density lipoprotein cholesterol; LDL-C: Low-density lipoprotein cholesterol; HPLC: High performance liquid chromatography; SD: Standard deviation.
\end{abstract}

\section{Acknowledgements}

Not applicable.

\section{Author contributions}

SHL and XXT analyzed and interpreted the patient data regarding the type 2 diabetes, and were the major contributors in writing the manuscript. YTL and BYW collect the data. ZSH and ZXL collected the data and contributed to the introduction. LP, YSL and JMZ contributed to the reviewed/edited the manuscript. YMC, JLL and JLZ made contributions to conception and design of this study and the edition of the manuscript. All authors read and approved the final manuscript.

\section{Funding}

This study was funded by National Key R\&D Program of China (2017YFA0105803), the National Natural Science Foundation of China (81770826, 81900320), the 5010 Clinical Research Projects of Sun Yat-sen University (2015015), the Key Area R\&D Program of Guangdong Province
(2019B020227003), the Science and Technology Plan Project of Guangzhou City (202007040003), the Guangdong Medical Research Foundation (C2019107, A2020142), the Fundamental Research Funds for the Central Universities (19ykpy40), and the Guangdong Basic and Applied Basic Research Foundation (2020A1515010599).

\section{Availability of data and materials}

The datasets used and/or analyzed during the current study are available from the corresponding author on reasonable request.

\section{Ethics approval and consent to participate}

Ethics approval was obtained from the third affiliated hospital of Sun Yat-sen University Network Ethics Committee. Informed consent was obtained from all participants.

\section{Consent for publication}

Not applicable.

\section{Competing interests}

The authors declare that they have no competing interests.

\section{Author details}

${ }^{1}$ Department of Cardiovascular Medicine, The Third Affiliated Hospital of Sun Yat-Sen University, Guangzhou 510630, China. ${ }^{2}$ Department of Endocrinology \& Metabolism, Guangdong Provincial Key Laboratory of Diabetology, The Third Affiliated Hospital of Sun Yat-Sen University, Guangzhou 510630, China. ${ }^{3}$ VIP Medical Service Center, The Third Affiliated Hospital of Sun Yat-Sen University, Guangzhou 510630, China. ${ }^{4}$ Department of Ultrasonography, The Third Affiliated Hospital of Sun Yat-Sen University, Guangzhou 510630, China.

Received: 8 June 2020 Accepted: 12 September 2020

Published online: 25 September 2020

\section{References}

1. Arnold SV, Bhatt DL, Barsness GW, Beatty AL, Deedwania PC, Inzucchi SE, Kosiborod M, Leiter LA, Lipska KJ, Newman JD, et al. Clinical management of stable coronary artery disease in patients with type 2 diabetes mellitus: a scientific statement from the American Heart Association. Circulation. 2020;141(19):e779-e806.

2. Deseive S, Straub R, Kupke M, Broersen A, Kitslaar PH, Stocker TJ, Massberg S, Hadamitzky M, Hausleiter J. Impact of diabetes on coronary artery plaque volume by coronary CT angiography and subsequent adverse cardiac events. J Cardiovasc Comput Tomogr. 2019;13(1):31-7.

3. Kim U, Leipsic JA, Sellers SL, Shao M, Blanke P, Hadamitzky M, Kim YJ, Conte $\mathrm{E}$, Andreini D, Pontone $\mathrm{G}$, et al. Natural history of diabetic coronary atherosclerosis by quantitative measurement of serial coronary computed tomographic angiography: results of the PARADIGM study. JACC Cardiovasc imaging. 2018;11(10):1461-71.

4. Voros S, Rinehart S, Qian Z, Joshi P, Vazquez G, Fischer C, Belur P, Hulten E, Villines TC. Coronary atherosclerosis imaging by coronary CT angiography: current status, correlation with intravascular interrogation and meta-analysis. JACC Cardiovasc Imaging. 2011:4(5):537-48.

5. Knuuti J, Ballo H, Juarez-Orozco LE, Saraste A, Kolh P, Rutjes AWS, Juni P, Windecker S, Bax JJ, Wijns W. The performance of non-invasive tests to rule-in and rule-out significant coronary artery stenosis in patients with stable angina: a meta-analysis focused on post-test disease probability. Eur Heart J. 2018;39(35):3322-30.

6. Danad I, Szymonifka J, Twisk JWR, Norgaard BL, Zarins CK, Knaapen P, Min JK. Diagnostic performance of cardiac imaging methods to diagnose ischaemia-causing coronary artery disease when directly compared with fractional flow reserve as a reference standard: a meta-analysis. Eur Heart J. 2017;38(13):991-8.

7. Gonzalez JA, Lipinski MJ, Flors L, Shaw PW, Kramer CM, Salerno M. Metaanalysis of diagnostic performance of coronary computed tomography angiography, computed tomography perfusion, and computed tomography-fractional flow reserve in functional myocardial ischemia assessment versus invasive fractional flow reserve. Am J Cardiol. 2015;116(9):1469-78.

8. Tang X, Li S, Wang Y, Wang M, Yin Q, Mu P, Lin S, Qian X, Ye X, Chen Y. Glycemic variability evaluated by continuous glucose monitoring system 
is associated with the 10-y cardiovascular risk of diabetic patients with well-controlled HbA1c. Clin Chim Acta. 2016;461:146-50.

9. Tang X, Zhong J, Zhang H, Luo Y, Liu X, Peng L, Zhang Y, Qian X, Jiang B, Liu J, et al. Visit-to-visit fasting plasma glucose variability is an important risk factor for long-term changes in left cardiac structure and function in patients with type 2 diabetes. Cardiovasc Diabetol. 2019;18(1):50.

10. Li S, Zheng Z, Tang X, Zhong J, Liu X, Zhao Y, Chen L, Zhu J, Liu J, Chen Y. Impact of $\mathrm{HbA1c}$ variability on subclinical left ventricular remodeling and dysfunction in patients with type 2 diabetes mellitus. Clin Chim Acta. 2020;502:159-66.

11. Lin CC, Yang CP, Li Cl, Liu CS, Chen CC, Lin WY, et al. Visit-to-visit variability of fasting plasma glucose as predictor of ischemic stroke: competing risk analysis in a national cohort of Taiwan Diabetes Study. BMC Med. 2014;12:165.

12. Muggeo M, Verlato G, Bonora E, Zoppini G, Corbellini M, de Marco R. Long-term instability of fasting plasma glucose, a novel predictor of cardiovascular mortality in elderly patients with non-insulin-dependent diabetes mellitus: the Verona Diabetes Study. Circulation. 1997;96(6):1750-4.

13. Muggeo M, Zoppini G, Bonora E, Brun E, Bonadonna RC, Moghetti P, Verlato G. Fasting plasma glucose variability predicts 10 -year survival of type 2 diabetic patients: the Verona Diabetes Study. Diabetes Care. 2000;23(1):45-50.

14. Hirakawa Y, Arima H, Zoungas S, Ninomiya T, Cooper M, Hamet P, Mancia G, Poulter N, Harrap S, Woodward M, et al. Impact of visit-to-visit glycemic variability on the risks of macrovascular and microvascular events and all-cause mortality in type 2 diabetes: the ADVANCE trial. Diabetes Care. 2014;37(8):2359-65.

15. Xu D, Fang H, Xu W, Yan Y, Liu Y, Yao B. Fasting plasma glucose variability and all-cause mortality among type 2 diabetes patients: a dynamic cohort study in Shanghai, China. Sci Rep. 2016;6:39633.

16. Lee CL, Sheu WH, Lee IT, Lin SY, Liang WM, Wang JS, Li YF. Trajectories of fasting plasma glucose variability and mortality in type 2 diabetes. Diabetes Metab. 2018;44(2):121-8.

17. Okada K, Hibi K, Gohbara M, Kataoka S, Takano K, Akiyama E, Matsuzawa Y, Saka K, Maejima N, Endo M, et al. Association between blood glucose variability and coronary plaque instability in patients with acute coronary syndromes. Cardiovasc Diabetol. 2015;14:111.

18. Teraguchi I, Imanishi T, Ozaki Y, Tanimoto T, Orii M, Shiono Y, Shimamura K, Ishibashi K, Yamano T, Ino Y, et al. Impact of glucose fluctuation and monocyte subsets on coronary plaque rupture. Nutr Metab Cardiovasc Dis. 2014;24(3):309-14.

19. Kuroda M, Shinke T, Sakaguchi K, Otake H, Takaya T, Hirota Y, Sugiyama D, Nakagawa M, Hariki H, Inoue T, et al. Effect of daily glucose fluctuation on coronary plaque vulnerability in patients pre-treated with lipid-lowering therapy: a prospective observational study. JACC Cardiovasc Interv. 2015;8(6):800-11.

20. Kashiyama K, Sonoda S, Muraoka Y, Suzuki Y, Kamezaki F, Tsuda Y, Araki M, Tamura M, Takeuchi M, Abe H, et al. Coronary plaque progression of non-culprit lesions after culprit percutaneous coronary intervention in patients with moderate to advanced chronic kidney disease: intravascular ultrasound and integrated backscatter intravascular ultrasound study. Int J Cardiovasc Imaging. 2015;31(5):935-45.

21. Gohbara M, Hibi K, Mitsuhashi T, Maejima N, Iwahashi N, Kataoka S, Akiyama E, Tsukahara K, Kosuge M, Ebina T, et al. Glycemic variability on continuous glucose monitoring system correlates with non-culprit vessel coronary plaque vulnerability in patients with first-episode acute coronary syndrome-optical coherence tomography study. Circ J. 2016;80(1):202-10.

22. Moss AJ, Williams MC, Newby DE, Nicol ED. The updated NICE guidelines: cardiac CT as the first-line test for coronary artery disease. Curr Cardiovasc Imaging Rep. 2017;10(5):15.

23. Alberti KG, Zimmet PZ. Definition, diagnosis and classification of diabetes mellitus and its complications. Part 1: diagnosis and classification of diabetes mellitus provisional report of a WHO consultation. Diabet Med. 1998;15(7):539-53.

24. Abbara S, Blanke P, Maroules CD, Cheezum M, Choi AD, Han BK, Marwan M, Naoum C, Norgaard BL, Rubinshtein R, et al. SCCT guidelines for the performance and acquisition of coronary computed tomographic angiography: a report of the society of Cardiovascular Computed Tomography Guidelines Committee: endorsed by the North American
Society for Cardiovascular Imaging (NASCI). J Cardiovasc Comput Tomogr. 2016;10(6):435-49.

25. Leipsic J, Abbara S, Achenbach S, Cury R, Earls JP, Mancini GJ, Nieman K, Pontone G, Raff GL. SCCT guidelines for the interpretation and reporting of coronary CT angiography: a report of the Society of Cardiovascular Computed Tomography Guidelines Committee. J Cardiovasc Comput Tomogr. 2014;8(5):342-58.

26. Boogers MJ, Broersen A, van Velzen JE, de Graaf FR, El-Naggar HM, Kitslaar PH, Dijkstra J, Delgado V, Boersma E, de Roos A, et al. Automated quantification of coronary plaque with computed tomography: comparison with intravascular ultrasound using a dedicated registration algorithm for fusion-based quantification. Eur Heart J. 2012;33(8):1007-166.

27. Muhlestein JB, Lappe DL, Lima JA, Rosen BD, May HT, Knight S, Bluemke DA, Towner SR, Le V, Bair TL, et al. Effect of screening for coronary artery disease using $\mathrm{CT}$ angiography on mortality and cardiac events in highrisk patients with diabetes: the FACTOR-64 randomized clinical trial. JAMA. 2014;312(21):2234-43.

28. Leber AW, Becker A, Knez A, de Ziegler F, Sirol M, Nikolaou K, Ohnesorge B, Fayad ZA, Becker CR, Reiser M, et al. Accuracy of 64-slice computed tomography to classify and quantify plaque volumes in the proximal coronary system: a comparative study using intravascular ultrasound. J Am Coll Cardiol. 2006;47(3):672-7.

29. Sun J, Zhang Z, Lu B, Yu W, Yang Y, Zhou Y, Wang Y, Fan Z. Identification and quantification of coronary atherosclerotic plaques: a comparison of 64-MDCT and intravascular ultrasound. AJR Am J Roentgenol. 2008;190(3):748-54.

30. Papadopoulou SL, Neefjes LA, Schaap M, Li HL, Capuano E, van der Giessen AG, Schuurbiers JC, Gijsen FJ, Dharampal AS, Nieman K, et al. Detection and quantification of coronary atherosclerotic plaque by 64-slice multidetector CT: a systematic head-to-head comparison with intravascular ultrasound. Atherosclerosis. 2011;219(1):163-70.

31. Voros S, Rinehart S, Qian Z, Vazquez G, Anderson H, Murrieta L, Wilmer C, Carlson H, Taylor K, Ballard W, et al. Prospective validation of standardized, 3-dimensional, quantitative coronary computed tomographic plaque measurements using radiofrequency backscatter intravascular ultrasound as reference standard in intermediate coronary arterial lesions: results from the ATLANTA (assessment of tissue characteristics, lesion morphology, and hemodynamics by angiography with fractional flow reserve, intravascular ultrasound and virtual histology, and noninvasive computed tomography in atherosclerotic plaques) I study. JACC Cardiovasc Interv. 2011;4(2):198-208.

32. Nakanishi R, Ceponiene I, Osawa K, Luo Y, Kanisawa M, Megowan N, Nezarat N, Rahmani S, Broersen A, Kitslaar PH, et al. Plaque progression assessed by a novel semi-automated quantitative plaque software on coronary computed tomography angiography between diabetes and non-diabetes patients: a propensity-score matching study. Atherosclerosis. 2016;255:73-9.

33. Won KB, Lee SE, Lee BK, Park HB, Heo R, Rizvi A, Lin FY, Kumar A, Hadamitzky M, Kim YJ, et al. Longitudinal assessment of coronary plaque volume change related to glycemic status using serial coronary computed tomography angiography: a PARADIGM (Progression of AtheRosclerotic PIAque Determ Ined by Computed TomoGraphic Angiography Imaging) substudy. J Cardiovasc Comput Tomogr. 2019;13(2):142-7.

34. Yang J, Dou G, Tesche C, De Cecco CN, Jacobs BE, Schoepf UJ, Chen Y. Progression of coronary atherosclerotic plaque burden and relationship with adverse cardiovascular event in asymptomatic diabetic patients. BMC Cardiovasc Disord. 2019:19(1):39.

35. Bayturan O, Tuzcu EM, Uno K, Lavoie AJ, Hu T, Shreevatsa A, Wolski K, Schoenhagen P, Kapadia S, Nissen SE, et al. Comparison of rates of progression of coronary atherosclerosis in patients with diabetes mellitus versus those with the metabolic syndrome. Am J Cardiol. 2010;105(12):1735-9.

36. Berry C, Noble S, Gregoire JC, Ibrahim R, Levesquie S, Lavoie MA, L'Allier $\mathrm{PL}$, Tardif JC. Glycaemic status influences the nature and severity of coronary artery disease. Diabetologia. 2010;53(4):652-8.

37. Slieker RC, van der Heijden A, Nijpels G, Elders PJM, t Hart LM, Beulens JWJ. Visit-to-visit variability of glycemia and vascular complications: the Hoorn Diabetes Care System cohort. Cardiovascular diabetology. 2019;18(1):170.

38. Zhou JJ, Schwenke DC, Bahn G, Reaven P, Investigators V. Glycemic variation and cardiovascular risk in the veterans affairs diabetes trial. Diabetes Care. 2018;41(10):2187-94. 
39. Cardoso CRL, Leite NC, Moram CBM, Salles GF. Long-term visit-to-visit glycemic variability as predictor of micro- and macrovascular complications in patients with type 2 diabetes: the Rio de Janeiro Type 2 Diabetes Cohort Study. Cardiovasc Diabetol. 2018;17:33.

40. Gorst C, Kwok CS, Aslam S, Buchan I, Kontopantelis E, Myint PK, Heatlie G, Loke Y, Rutter MK, Mamas MA. Long-term glycemic variability and risk of adverse outcomes: a systematic review and meta-analysis. Diabetes Care. 2015;38(12):2354-69.

41. Takao T, Matsuyama Y, Yanagisawa H, Kikuchi M, Kawazu S. Association between $\mathrm{HbA} 1 \mathrm{c}$ variability and mortality in patients with type 2 diabetes. J Diabetes Complicat. 2014;28(4):494-9.

42. Wan EYF, Fung CSC, Fong DYT, Lam CLK. Association of variability in hemoglobin A1c with cardiovascular diseases and mortality in Chinese patients with type 2 diabetes mellitus - a retrospective population-based cohort study. J Diabetes Complicat. 2016;30(7):1240-7.

43. Takao T, Matsuyama Y, Suka M, Yanagisawa H, Iwamoto Y. The combined effect of visit-to-visit variability in $\mathrm{HbA} 1 \mathrm{c}$ and systolic blood pressure on the incidence of cardiovascular events in patients with type 2 diabetes. BMJ Open Diabetes Res Care. 2015;3(1):e000129.

44. Bouchi R, Babazono T, Mugishima M, Yoshida N, Nyumura I, Toya K, Hayashi T, Hanai K, Tanaka N, Ishii A, et al. Fluctuations in HbA1c are associated with a higher incidence of cardiovascular disease in Japanese patients with type 2 diabetes. J Diabetes Investig. 2012;3(2):148-55.

45. Ferreira L, Moniz AC, Carneiro AS, Miranda AS, Fangueiro C, Fernandes D, Silva I, Palhinhas I, Lemos J, Antunes J, et al. The impact of glycemic variability on length of stay and mortality in diabetic patients admitted with community-acquired pneumonia or chronic obstructive pulmonary disease. Diabetes Metab Syndr. 2019;13(1):149-53.

46. Kobayashi D, Noto H, Takahashi O, Shimbo T. Glycemic variability and subsequent malignancies among the population without diabetes. Diabetes Res Clin Pract. 2020;159:107987.

47. Besch G, Pili-Floury S, Morel C, Gilard M, Flicoteaux G, Salomon L, Perrotti A, Meneveau N, Chocron S, Schiele F, et al. Impact of post-procedural glycemic variability on cardiovascular morbidity and mortality after transcatheter aortic valve implantation: a post hoc cohort analysis. Cardiovasc Diabetol. 2019;18(1):27.

48. Yokota S, Tanaka H, Mochizuki Y, Soga F, Yamashita K, Tanaka Y, Shono A, Suzuki M, Sumimoto K, Mukai J, et al. Association of glycemic variability with left ventricular diastolic function in type 2 diabetes mellitus. Cardiovasc Diabetol. 2019;18(1):166

49. Nusca A, Tuccinardi D, Proscia C, Melfi R, Manfrini S, Nicolucci A, Ceriello A, Pozzilli P, Ussia GP, Grigioni F, et al. Incremental role of glycaemic variability over $\mathrm{HbA} 1 \mathrm{C}$ in identifying type 2 diabetic patients with high platelet reactivity undergoing percutaneous coronary intervention. Cardiovasc Diabetol. 2019;18(1):147.

50. Marx N, Wöhrle J, Nusser T, Walcher D, Rinker A, Hombach V, Koenig W, Höher M. Pioglitazone reduces neointima volume after coronary stent implantation: a randomized, placebo-controlled, double-blind trial in nondiabetic patients. Circulation. 2005;112(18):2792-8.

51. Kuramitsu S, Miyauchi K, Yokoi H, Suwa S, Nishizaki Y, Yokoyama T, Nojiri S, Iwabuchi M, Shirai S, Ando K, et al. Effect of sitagliptin on plaque changes in coronary artery following acute coronary syndrome in diabetic patients: The ESPECIAL-ACS study. J Cardiol. 2017:69(1):369-76.

52. Kim NH, Kim DL, Kim KJ, Kim NH, Choi KM, Baik SH, Kim SG. Effects of vildagliptin or pioglitazone on glycemic variability and oxidative stress in patients with type 2 diabetes inadequately controlled with metformin monotherapy: a 16-week, randomised, open label, pilot study. Endocrinol Metab. 2017;32(2):241-7.
53. Fuchigami A, Shigiyama F, Kitazawa T, Okada Y, Ichijo T, Higa M, Hiyoshi T, Inoue I, Iso K, Yoshii H, et al. Efficacy of dapagliflozin versus sitagliptin on cardiometabolic risk factors in Japanese patients with type 2 diabetes: a prospective, randomized study (DIVERSITY-CVR). Cardiovasc Diabetol. 2020;19(1):1.

54. Henry RR, Strange P, Zhou R, Pettus J, Shi L, Zhuplatov SB, Mansfield T, Klein D, Katz A. Effects of dapagliflozin on 24-hour glycemic control in patients with type 2 diabetes: a randomized controlled trial. Diabetes Technol Ther. 2018;20(11):715-24.

55. Yahagi K, Kolodgie FD, Lutter C, Mori H, Romero ME, Finn AV, Virmani R. Pathology of human coronary and carotid artery atherosclerosis and vascular calcification in diabetes mellitus. Arterioscler Thromb Vasc Biol. 2017;37(2):191-204.

56. Libby P, Ridker PM, Maseri A. Inflammation and atherosclerosis. Circulation. 2002;105(9):1135-43.

57. Kobayashi S, Inoue N, Ohashi Y, Terashima M, Matsui K, Mori T, Fujita H, Awano K, Kobayashi K, Azumi H, et al. Interaction of oxidative stress and inflammatory response in coronary plaque instability: important role of C-reactive protein. Arterioscler Thromb Vasc Biol. 2003;23(8):1398-404.

58. Zouridakis E, Avanzas P, Arroyo-Espliguero R, Fredericks S, Kaski JC. Markers of inflammation and rapid coronary artery disease progression in patients with stable angina pectoris. Circulation. 2004;110(13):1747-53.

59. Chang CM, Hsieh CJ, Huang JC, Huang IC. Acute and chronic fluctuations in blood glucose levels can increase oxidative stress in type 2 diabetes mellitus. Acta Diabetol. 2012;49(Suppl 1):S171-177.

60. Keating ST, El-Osta A. Glycemic memories and the epigenetic component of diabetic nephropathy. Curr Diabetes Rep. 2013;13(4):574-81.

61. Monnier L, Mas E, Ginet C, Michel F, Villon L, Cristol JP, Colette C. Activation of oxidative stress by acute glucose fluctuations compared with sustained chronic Hyperglycemia in patients with type 2 diabetes. JAMA. 2006:295(14):1681-7.

62. Maeda M, Hayashi T, Mizuno N, Hattori Y, Kuzuya M. Intermittent high glucose implements stress-induced senescence in human vascular endothelial cells: role of superoxide production by NADPH oxidase. PLoS ONE. 2015;10(4):e0123169.

63. Sun L-Q, Chen Y-Y, Wang X, Li X-J, Xue B, Qu L, Zhang T-T, Mu Y-M, Lu J-M. The protective effect of Alpha lipoic acid on Schwann cells exposed to constant or intermittent high glucose. Biochem Pharmacol. 2012;84(7):961-73.

64. Zhong VW, Juhaeri J, Cole SR, Shay CM, Gordon-Larsen P, Kontopantelis E, Mayer-Davis EJ. HbA(1C) variability and hypoglycemia hospitalization in adults with type 1 and type 2 diabetes: a nested case-control study. J Diabetes Complicat. 2018;32(2):203-9.

65. Ratter JM, Rooijackers HM, Tack CJ, Hijmans AG, Netea MG, de Galan BE, Stienstra R. Proinflammatory effects of hypoglycemia in humans with or without diabetes. Diabetes. 2017;66(4):1052-61.

66. Gogitidze Joy N, Hedrington MS, Briscoe VJ, Tate DB, Ertl AC, Davis SN. Effects of acute hypoglycemia on inflammatory and pro-atherothrombotic biomarkers in individuals with type 1 diabetes and healthy individuals. Diabetes Care. 2010;33(7):1529-35.

67. Reno CM, Daphna-Iken D, Chen YS, VanderWeele J, Jethi K, Fisher SJ. Severe hypoglycemia-induced lethal cardiac arrhythmias are mediated by sympathoadrenal activation. Diabetes. 2013;62(10):3570-81.

\section{Publisher's Note}

Springer Nature remains neutral with regard to jurisdictional claims in published maps and institutional affiliations. 